\title{
Husserl on Hallucination: A Conjunctive Reading
}

\author{
MATT E. M. B OWER*
}

\begin{abstract}
Several commentators have recently attributed conflicting accounts of the relation between veridical perceptual experience and hallucination to Husserl. Some say he is a proponent of the conjunctive view that the two kinds of experience are fundamentally the same. Others deny this and purport to find in Husserl distinct and non-overlapping accounts of their fundamental natures, thus committing him to a disjunctive view. My goal is to set the record straight. Having first briefly laid out the problem under discussion and the terms of the debate, I then review the proposals that have been advanced, disposing of some and marking others for further consideration later in the paper. A. D. Smith's disjunctive reading is among the latter. I discuss it at length, arguing that Smith fails to show that Husserl's views on perceptual experience entail a form of disjunctivism. Following that critical discussion, I present a case for a conjunctive reading of Husserl's account of perceptual experience.
\end{abstract}

KEYWORDS Edmund Husserl, perception, hallucination, disjunctivism, phenomenology

\section{THE NATURE OF H A L L U C I N A T I O N}

One of Edmund Husserl's theoretical priorities throughout his philosophical career was to understand the nature of perceptual experience. His analyses of perceptual experience had a profound impact on subsequent thinkers in the phenomenological tradition, such as Aron Gurwitsch and Maurice MerleauPonty. Naturally, his account of perception remains a topic of discussion among Husserl scholars. Despite the attention it has received over many decades, Husserl interpreters diverge considerably in how they understand his views and their relation to current debates in the philosophy of perception. A case in point is Husserl's view on the relation between veridical perceptual experience and hallucination, which I will focus on in what follows. There are at least three competing interpretations. Not all of them deserve equal attention, and I will argue that the conjunctive interpretation in particular, after reflection on relevant texts, is clearly preferable over the others.

\footnotetext{
* Matt Bower is Lecturer in Philosophy at Texas State University.
} 
Let us begin by doing some stage setting. In this section, I lay out the terms of the contemporary debate within which Husserl scholars have tried to situate his view. Next, I give an overview of the various positions that have been attributed to Husserl (section 2), identifying two that are particularly promising, one of which I then suggest ultimately fails in its aspiration to establish that Husserl's views about perception entail disjunctivism (section 3). The conjunctive view, I argue, follows much more straightforwardly from Husserl's writings on the matter and is the right view to attribute to him (section 4).

While hallucination poses many problems for philosophers (e.g. concerning knowledge of an external world), in recent decades philosophers of perception have been concerned especially with getting a grip on its metaphysical nature. All parties agree at least on what the target phenomenon is and how it is distinct from certain other closely related phenomena. What we are concerned with in discussing hallucination are experiences where there appears to be something before you that is not in fact there at all. Presumably, when Jean-Paul Sartre took mescaline and began to see crabs, he was hallucinating. ${ }^{1}$ There were no crabs in his vicinity. Hallucination thus differs from illusion, which is the experience of something that is in fact before you, but as other than it really is, like when a stick partially submerged in water looks bent to you. Experiences of either sort, whether hallucinatory or illusory, are commonly called "the bad cases," since in them the world appears to you to be other than it really is. Veridical perceptual experience, then, represents "the good case," presenting you with something that really is before you as it in fact is, the sort of experience I expect you are now having.

Now, the question is what to say about the metaphysical nature of hallucination. That question is typically asked with a reasonable assumption in the background, namely, that "perfect hallucinations" are possible. A perfect hallucination is one that is indistinguishable from a veridical perceptual experience. In principle, for every possible veridical perceptual experience there is a corresponding hallucination that cannot be distinguished from it. Nothing about the experience gives it away as non-standard in any respect. Allowing for the possibility of perfect hallucination is pertinent because it puts pressure on how we characterize the nature of hallucination. When two kinds of thing can perfectly resemble one another, it is natural to think that is because they have a common nature. It is at least prima facie plausible to say, then, that hallucination and veridical perceptual experience are fundamentally the same kind of experience.

Those who adopt this position are called conjunctivists. ${ }^{2}$ Of course, it is not enough to say the two kinds of experience share their fundamental nature. A plausible account of what that shared nature consists of is needed, too. The usual suggestion is that what is common to a veridical perceptual experience and its matching perfect hallucination is their intentional content. The content of a mental state is supposed to determine what it is about, and, on this view, perceptual experiences can have the same content whether or not their targets

\footnotetext{
${ }^{1}$ See John Gerassi, Talking with Sartre, 62-63.

${ }^{2}$ For defenses of the conjunctive view, see Howard Robinson, Perception and "The Failure of"; Tyler Burge, "Disjunctivism and Perceptual Psychology"; and Katalin Farkas, "Indiscriminability."
} 
are present. Given the myriad items surrounding you and the even greater variety of features and properties they possess, something about your mental state must do the work of accounting for which objects you are actually directed toward and in what respects (i.e. with regard to which features or properties). Intentional content is intended to do just that work. The standard conjunctivist line is that all perceptual experiences, whether veridical or hallucinatory, are of a piece in that their essence is their content, and they do not differ except in whether that content fits with the way things are, which is a secondary matter as far as the natures of the experiences are concerned.

The primary opponent of the conjunctivist is the disjunctivist. ${ }^{3}$ On the disjunctive view, as you will have guessed, perceptual experience is not an ultimately homogeneous kind. For the disjunctivist, a token perceptual experience is either a veridical perceptual experience, accounted for in one way, or a hallucination, accounted for in some fundamentally different way, and never both. There is no consensus about what to say concerning the nature of hallucination, or whether we can say anything more than that it can be indistinguishable from veridical perceptual experience. But it is generally agreed that what sets the two apart is that your experience in veridical perception is in some sense object-dependent. Some say that it is object-dependent because the experience consists of a relation to external, worldly particulars, which must therefore exist to stand in that relation, while others say it is because the experience has content that for one reason or another requires the targeted object's presence. Note that one can hold both that perceptual experience has content and also that it involves a real relation. ${ }^{4}$ It is neither true that attributing content to perceptual experience immediately commits you to a conjunctive view, ${ }^{5}$ nor that conceiving perceptual experience as a real relation immediately entails a disjunctive view. ${ }^{6}$

\section{HUSSERL A N D H IS INTERPRETERS: A N OVERVIEW}

Now, how do things stand with Husserl? Is he obviously-or not-so-obviously-a proponent of the conjunctive or disjunctive view? There is now a minor literature attempting to address this question. No one claims that Husserl is a self-styled conjunctivist or disjunctivist, but only that he, at most, holds one of these views avant la lettre or, more likely, that disparate claims he makes jointly entail one view or the other. The debate is thus about whether his "views ultimately commit him to [these] position [s]," as Smith is careful to say. ${ }^{7}$ There was little in the way of sustained treatment of Husserl's views on the topic until the last decade. Yet there are scattered and typically brief bits of Husserl interpretation that are worth

${ }^{3}$ For defenses of disjunctivism, see Paul Snowdon, "Perception, Vision and Causation"; John McDowell, "Criteria, Defeasibility \& Knowledge"; and Michael G. M. Martin, "The Transparency of Experience."

${ }^{4}$ See Susanna Schellenberg, "The Relational and Representational Character of Perceptual Experience"; and Heather Logue, "Experiential Content and Naïve Realism."

${ }^{5}$ See Heather Logue, "Good News for the Disjunctivist."

${ }^{6}$ See Mark Johnston, "The Function of Sensory Awareness"; and Rami Ali, "Does Hallucination Involve Perceiving."

${ }^{7}$ A. D. Smith, "Husserl and Externalism," 33 I. 
mentioning, if only to give a sense of the difficulty facing contemporary Husserl interpreters interested in exploring his views' bearing on the disjunctivism/ conjunctivism controversy.

First, a brief tour of studies that favor a conjunctive reading of Husserl. In the older literature, this reading seems to be far more common than the alternative. Dagfinn Føllesdal provides a summary report on Husserl's view of hallucination (and illusion) that seems to construe hallucination as a species of perceptual experience not fundamentally distinct from veridical perception, yet without offering any citation of Husserl's writings. ${ }^{8}$ David W. Smith and Ronald McIntyre supply the missing textual support and argue that the "intentional relation," on Husserl's telling, is only a quasi-relation, grounded solely in the intrinsic features of an experience independent of how things stand in reality, such as whether experience presents things as they are or that exist at all. ${ }^{9}$

Barry Smith and Kevin Mulligan, although neither explicitly touching on the issue of hallucination nor primarily focusing on perceptual experience, nevertheless contribute to the discussion by attributing a non-relational account of intentionality to Husserl. ${ }^{10}$ That account, if correct, renders unlikely Husserl's being a disjunctivist, insofar as perception is an intentional and, thus, nonrelational state, that is, one not necessarily requiring its relatum's existence. ${ }^{11}$ In keeping with that trend, John Bickle and Ralph Ellis claim that, for Husserl, whether a token perceptual experience is veridical or hallucinatory in nature is a contingent, empirical matter to be determined a posteriori and not based on any intrinsic feature of the experience. ${ }^{12}$ These authors are largely preoccupied with understanding Husserl's views as spelled out in Ideas I, but a similar reading is available for the Logical Investigations. ${ }^{13}$ I think that this is the correct reading of Husserl and will provide further support for it below (section 3.5 and section 4 ).

Now let us turn to see what Husserl interpreters have said that might be marshalled to support a disjunctive reading. Mulligan, in passing, tentatively suggests that Husserl goes in for disjunctivism based on a passage from the Logical Investigations. ${ }^{14}$

Mulligan is prompted by the following remark of Husserl's to entertain a disjunctive reading: "It need only . . . be acknowledged that the intentional object of a presentation is the same as its actual object, and on occasion as its external object, and that it is absurd to distinguish between them." ${ }^{5}$ 'Actual' here should not be confused with 'real' or 'actually existing,' as this is a general claim about all intentional states, regardless of whether the intentional object "exists or is

${ }^{8}$ Føllesdal, "Husserl's Theory of Perception," 95-96.

${ }^{9}$ David W. Smith and Ronald McIntyre, Husserl and Intentionality, 9I-92; see also David W. Smith, "Perception, Context, and Direct Realism," I7-I8.

${ }^{10}$ See Barry Smith, "Acta cum Fundamentalis in Re"; and Kevin Mulligan and Barry Smith, "A Relational Theory of the Act."

${ }^{11}$ Mulligan and Smith, "A Relational Theory of the Act," I $25-27$.

${ }^{12}$ John Bickle and Ralph Ellis, "Phenomenology and Cortical Microstimulation," I 54-57.

${ }^{13}$ See David Bell, "Reference, Experience, and Intentionality"; and Herman Philipse, "The Concept of Intentionality."

${ }^{14}$ Kevin Mulligan, "Perception," 213-I6; and Peter Poellner, "Consciousness in the World," 446.

${ }^{15}$ Husserl, LI 2:I 27. 
imaginary or absurd. ${ }^{16}$ For that same reason, it is not obvious how the claim would entail any difference between veridical perceptual experience and hallucination. The claim, whatever it amounts to, applies to both equally. And, importantly, Mulligan denies that Husserl avows or could avow the kind of disjunctivism that we are interested in, according to which veridical perceptual experiences are inherently object-dependent and hallucinations are not. ${ }^{17}$

Of more promise, at first glance, is the story developed by Jitendra Mohanty, ${ }^{18}$ in which he-explicitly against Føllesdal and implicitly also against the views of Barry Smith, Mulligan, David Smith, and McIntyre-attributes a dyadic actobject account of intentionality to Husserl as opposed to the act-content-object account many interpreters take Husserl to hold. Mohanty's view-the core of it, anyway, namely, the appeal to a dyadic take on intentionality-is shared by John Drummond, Uwe Meixner, and Dan Zahavi. ${ }^{19}$ On that view, perceptual experience is inherently relational and object-involving, unlike the act-content-object view, where the content, as it were, stands in for the object, which may or may not be present as the experience presents it without affecting the experience. ${ }^{20}$ Mohanty and those just cited who accept this interpretation are concerned with Husserl's post-Ideas I view, although similar claims have been made about his view in the Logical Investigations and writings prior to that. ${ }^{21}$

The talk of relations by Mohanty and others is a red herring, however. There are relations and there are relations. The kind of relation needed to ground disjunctivism is a real relation, one obtaining between two really existing relata. The relation posited by Mohanty and others is expressly not like that.

As they conceive of it, the perceptual relation is supposed to account for the good case (veridical perceptual experience) and the bad case (hallucination or illusion). ${ }^{22}$ Mohanty goes so far as to say that we cannot even distinguish, on Husserl's view, the objects of perceptual experience and hallucination as different in kind, that is, as existing or not existing (à la Meinongian objects, perhaps), ${ }^{23}$ or as particulars or universals (as in Johnston's account).$^{24}$ George Heffernan and Andrea Marchesi describe the perceptual relation as "existentially neutral" with respect to its objects. ${ }^{25}$ In other words, those who posit a perceptual relation in this sense go above and beyond to ensure continuity between veridical perceptual experience and hallucination. Such a view is at odds with contemporary, disjunctivism-friendly relational theories, which are not existentially neutral and

\footnotetext{
${ }^{16}$ Husserl, $L I$ 2:I 27

${ }^{17}$ Mulligan "Perception," 2I 4-I 5; and Poellner, "Consciousness in the World," 426n2 I.

${ }^{18}$ See Jitendra Mohanty, "Noema and Essence."

${ }^{19}$ See John Drummond, "Intentionality without Representation" and "The Doctrine of the Noema”; Uwe Meixner, "Husserl's Classical Conception of Intentionality"; and Zahavi, Husserl's Legacy.

${ }^{20}$ Mohanty, "Noema and Essence," 54.

${ }^{21}$ See Andrea Marchesi, "Husserl's Early Theory of Intentionality"; and George Heffernan, "The Paradox of Objectless Presentations."

${ }^{22}$ Mohanty, "Noema and Essence," 5 I and 54. See also Marchesi, "Husserl's Early Theory of Intentionality"; and Heffernan, "The Paradox of Objectless Presentations."

${ }^{23}$ Mohanty "Noema and Essence," 54.

${ }^{24}$ See Mark Johnston, "The Function of Sensory Awareness."

${ }^{25}$ Heffernan, "The Paradox of Objectless Presentations," 80; and Marchesi, "Husserl's Early Theory of Intentionality," I7.
} 
for that reason tend to be bundled up with a disjunctive account of perceptual experience.

Relational readings like Mohanty's cannot without further explanation be appealed to as a basis for a disjunctive reading of Husserl. They lead to the same conclusion as the non-relational readings already briefly described. They differ in how they understand Husserl's view on the fundamental nature of perceptual experience, but they both accept that whatever that view is, it is equally true of both veridical perceptual experience and hallucination. Because the distinction between relational and non-relational readings maps fairly well onto the distinction between so-called 'East Coast' and 'West Coast' interpretations of Husserl's notion of noema, respectively, it may be that the issue of how to understand the noema is orthogonal to the issue of his view of the relation between veridical perceptual experience and hallucination.

Perhaps that should not be surprising, if true. Holding a relational view of perception-even where the relation in question is a real relation-does not by itself commit you to disjunctivism, and neither does admitting mental representation into perceptual experience alone qualify you as a proponent of the conjunctive view. The point is that very different views about the nature of veridical perceptual experience can be made to cohere with either view of its relation to hallucination. So, taking a side in one of these debates (i.e. about the noema and about hallucination as Husserl conceives it) does not necessarily entail taking a side on the other. ${ }^{26}$

There is another relational reading of Husserl's view on perceptual experience that leads in a different direction than the readings already described. Drummond and Zahavi, like Mohanty, take intentionality in Husserl to consist of a dyadic act-object relation. They do not explicitly endorse or rule out Husserl's being a conjunctivist or disjunctivist. Yet they attribute claims to him that put him at odds, at least, with the typical disjunctivist. For instance, they both deny that perfect hallucination, that is, hallucination that is indistinguishable from some token veridical perceptual experience, is possible on Husserl's view and assert that all experience, even hallucination, is at least partly related to really existing objects, albeit not necessarily the objects targeted by the experience in question. ${ }^{27}$ So, on their reading, it looks like Husserl might agree with Rami Ali that hallucination is a special case of illusion. ${ }^{28}$ However, the disjunctivist typically handles illusion differently than hallucination by granting it the status of (misleading) perceptual experience. ${ }^{29}$

If Drummond and Zahavi are right, then Husserl may hold neither a conjunctive nor disjunctive view, but rather a third view that Ali dubs "illusionism," namely, the view that hallucinations are illusions, which, in turn, belong to the same fundamental kind as veridical perceptual experience. ${ }^{30}$ As interesting as this

\footnotetext{
${ }^{26}$ Thanks to the anonymous reviewer who pressed for further clarification on this point.

${ }^{27}$ Drummond "Intentionality without Representation," I 25 and I28-30; and Zahavi, Husserl's Legacy, 88-89.

${ }^{28}$ See Rami Ali, "Does Hallucination Involve Perceiving?"

${ }^{29}$ See Brewer, Perception and its Objects; and Genone, "Appearance and Illusion."

${ }^{30}$ See Ali, "Does Hallucination Involve Perceiving?"
} 
proposal is, Drummond's discussion is only Husserl-inspired and Zahavi's remarks are extremely cursory and take their cue from Drummond. It is not clear how exactly hallucination is supposed to consist in a relation to the world, yet not to the object the hallucination seems to present to the perceiver, and no textual support is provided for thinking that Husserl says this about hallucination or that his views have this as an implication. It is hard to see how Sartre's hallucinated crabs could have showed up for him by virtue of any relation to his surroundings. In typical relational accounts of illusion (e.g. as developed by James Genone and Bill Brewer) ${ }^{31}$ illusory appearances are explained in terms of ways that worldly objects or properties can appear or look thanks to certain properties possessed by these same objects or properties. For instance, that a white object looks red when red light is projected onto it is explained by some property of the white object. But it seems unlikely that any property or object in the scene before Sartre makes intelligible his experience of crabs before him. No candidate comes to mind and the more natural explanation is to appeal to Sartre's subjective constitution rather than how he is presently related to the scene before him. Extending the relational account of illusion to cover hallucination thus does not look very promising. Ultimately, I find this reading of Husserl unlikely based on the evidence I will present below for a conjunctive reading (section 3.5 and section 4 ).

The existing literature, especially going back more than a decade from now, despite its often fragmentary and overly general (i.e. addressing intentionality and not perceptual experience in particular) character nevertheless gives the impression that Husserl opts for some form of the conjunctive view. At least, that is the best developed and most plausible reading advanced so far. Roughly in the last decade, a small handful of articles have appeared that offer sustained, direct, and more textually-grounded interpretations of Husserl's view of veridical perceptual experience and hallucination. That is no doubt at least partly because, on the one hand, the relational view, which far more often than not is saddled with disjunctivism, has attracted a great deal of attention due its recent defense by, inter alia, Michael G. M. Martin, John Campbell, Charles Travis, and Bill Brewer, ${ }^{32}$ and, on the other hand, because of the relatively recent publication of relevant works by Husserl in English. ${ }^{33}$

A. D. Smith's 2008 article is something of a landmark piece on the topic, which has set the tone for several others. ${ }^{34}$ Smith defends a disjunctivist reading of Husserl that has received support and refinement from Walter Hopp and favorable mention by Peter Poellner, Zahavi, and Søren Overgaard. ${ }^{35}$ (Although Zahavi prefers a view closer to Mohanty's ${ }^{36}$ he apparently holds that if perfect hallucinations were possible, then Smith's story would be largely correct, and thus his endorsement

\footnotetext{
${ }^{31}$ See Brewer, Perception and its Objects; and Genone, "Appearance and Illusion."

${ }^{32}$ See, respectively, Martin, "The Transparency of Experience"; Campbell Reference and Consciousness; Travis, "The Silence of the Senses"; and Brewer, "Perception and Content."

${ }^{33}$ See, for instance, Husserl, Hua I6/Thing and Space, Hua I9/LI 2, and Hua 23/Phantasy.

${ }^{34}$ See Smith, "Husserl and Externalism."

${ }^{35}$ See, respectively, Walter Hopp, Perception and Knowledge and its favorable mention in Poellner, "Consciousness in the World"; Zahavi, Husserl's Legacy; and Søren Overgaard, "Perceptual Error, Conjunctivism, and Husserl."

${ }^{36}$ See Mohanty, "Noema and Essence."
} 
is qualified and conditional.) I will return to Smith's reading below and consider it in detail, arguing that the claims he thinks entail disjunctivism on Husserl's part do not in fact do that (section 3). Yet, as Overgaard notes, ${ }^{37}$ Smith's account enjoys significant advantages over other recent proposals, which are too hasty in attributing a conjunctive or, at least, a non-disjunctive view to Husserl. I concur with Overgaard's judgment about the views of Claude Romano and Andrea Staiti, although I happen to agree with Romano's conclusion.

Overgaard convincingly shows that Romano infers too hastily from Husserl's many well-known remarks to the effect that any perceptual experience could turn out to be non-veridical (i.e. hallucinatory or illusory) that, for Husserl, no kind of perceptual experience is inherently object-involving. However, something more or less equivalent to the former claim is accepted by all parties to the discussion, who grant that hallucinations, at least in principle, can perfectly resemble veridical perceptual experiences, and so nothing decisive follows from it. ${ }^{38}$ Staiti's error is to premise his account on a claim that is both highly implausible and mistakenly attributed to Husserl, namely, roughly, that hallucinations exist only by virtue of our retroactive identification of them as such. ${ }^{39}$ That claim, too, is supposed to be an implication of the very same remarks of Husserl's Romano bases his interpretation on, which, on closer analysis, it is not. The fact that a given perceptual experience does or can turn out to be hallucinatory or illusory does not by itself entail that its eventual turning out that way is what makes it hallucinatory or illusory. Surely, you can fail to discover that you have suffered a non-veridical experience. Staiti ignores the important distinction between the event of misperception (hallucination or illusion) and the experience of misperception. ${ }^{40}$

\section{SMITH'S D I J UNCTIVE REA D ING OF H USSERL}

I will now give a condensed run-down of A. D. Smith's case for thinking Husserl is a disjunctivist, ${ }^{41}$ which I will then evaluate. I will not dispute that Smith is correct in attributing the views he does to Husserl, but rather whether those "views ultimately commit him to this position" (i.e. disjunctivism), borrowing Smith's phrase again. ${ }^{42}$ What he would cull from Husserl's writings as criteria for distinguishing veridical perceptual experience and hallucination do not really set the two kinds of experience apart and, if we allow that they do for the sake of argument, it still does not follow that the two fundamentally differ in nature.

Smith begins by observing that a perceptual experience is a temporally extended act directed continuously at a particular object as one and the same object throughout its duration. ${ }^{43}$ The experience, moreover, is open-ended, containing

\footnotetext{
${ }^{37}$ See Overgaard, "Perceptual Error, Conjunctivism, and Husserl."

${ }^{38}$ Overgaard, "Perceptual Error, Conjunctivism, and Husserl," I 2-I3; and Romano, "Must Phenomenology Remain Cartesian?," 437-38.

${ }^{39}$ Overgaard, "Perceptual Error, Conjunctivism, and Husserl," I4-I 5; and Staiti, "On Husserl's Alleged Cartesianism," I 3 I-33.

${ }^{40}$ Izchak Miller, "Perceptual Reference," 46-5 I.

${ }^{41}$ Smith, "Husserl and Externalism," 322-3 I; and Hopp, Perception and Knowledge, I80-88.

${ }^{42}$ Smith, "Husserl and Externalism," 33 I.

${ }^{43}$ Smith, "Husserl and Externalism," 220-2 I.
} 
an implicit awareness of further possible perceptual experience, either continuous or discontinuous with it. ${ }^{44}$ If continuous, the experience keeps identifying the object as the same and, if discontinuous, it re-identifies the object as the same. A given experience, in fact, bears an implicit awareness of all possible continuous identifications or independent reidentifications of the object in perceptual experience as one and the same object. ${ }^{45}$

Veridical and hallucinatory experiences differ in their relation to such systems of possible experience. Smith suggests that this follows from a close examination of their respective relations to such systems of possible experience. Both kinds of experience bear an implicit and, importantly, indeterminate awareness of some such system. But, in veridical perceptual experience the system is ultimately a harmonious one identifying a real object, whereas in hallucination it is unharmonious and identifies an unreal, hallucinated object. ${ }^{46}$ Smith thus arrives at a criterion for determining whether an experience is veridical or hallucinatory. For this criterion to make sense, we will need to unpack his idea of what it means for a system of possible experience to be harmonious. For now, I will give just a cursory gloss. I will follow up with a more careful explication in my critical discussion below.

To be harmonious, in the relevant sense, is for all experiences within a given system to be consistent with each other in terms of how the relevant object is presented, allowing, of course, for perceptual registration of changes in the object or of further of its properties not previously experienced. ${ }^{47} \mathrm{~A}$ system of experiences is not merely harmonious but ultimately harmonious if some subset of its members is inconsistent (i.e. at least one mischaracterizes the object and is illusory) and another, overlapping subset of its members resolves the inconsistency. Resolution requires a possible experiential sequence where an illusory mischaracterization of the object is followed up by a correct characterization.

Veridical perceptual experiences, then, are inherently directed toward actually existing objects. They are not by nature wholly veridical because they tolerate illusion. But they are at least partially veridical to the extent that they are inherently object-involving, that is, the object they seem to present is always actually present, regardless of whether it appears as it is in all respects. Such experiences are inherently object-involving because they are individuated by reference to systems of possible experience harmoniously tracking the identity of the same object. The same cannot be said for hallucination, because, necessarily, Smith thinks, their corresponding system of possible experiences contain possible experiences that reveal the hallucinated object as such. ${ }^{48}$ On Smith's reading, therefore, Husserl's account of veridical perceptual experience and hallucination commits him to the view that they not only differ, but differ fundamentally, in that, thanks to the character of their respective systems of possible experience, the former is essentially object-involving and the latter is not.

\footnotetext{
${ }^{44}$ Smith, "Husserl and Externalism," 324-25.

${ }^{45}$ Smith, "Husserl and Externalism," 325-27.

${ }^{46}$ Smith, "Husserl and Externalism," 330-3 I.

${ }^{47}$ Smith, "Husserl and Externalism," 228-30.

${ }^{48}$ Smith, "Husserl and Externalism," 329-3 I.
} 
Smith's account runs into trouble, first, because there are counterexamples to his claim that hallucinations are by nature unharmonious. That claim is important because its lack of harmony is what is supposed to set apart hallucinations as a fundamentally different kind of experience from veridical perceptual experience. Suppose a hallucination is produced by, to put it crudely, certain wires crossing in the brain. The hallucination thus produced lasts for 5 seconds and, as you talk to a friend, what you hallucinate is a butterfly lazily passing through your field of vision. It enters from the left, disappears momentarily behind your friend's head, only to reappear momentarily as you would expect and then take leave of your field of vision on the right. It makes no great impression on you. In fact, you do not even realize you have hallucinated.

Already in the hallucination there is a system of experiences. There are at least two that present the butterfly to you. Each is temporally extended. In the first, you register the butterfly (minimally, as a projectile object) and maintain perceptual contact with it for a while as one and the same thing. Then, after a brief disappearance, it reemerges and you perceptually reidentify it as the very same entity.

The question is whether it is true that the experience of the butterfly necessarily belongs to an unharmonious system of possible perceptions. No doubt, it fails to harmonize in some sense. If you ask your fiend whether they saw the butterfly or remark on it in some other way, they will fail to lend any support to your experience and may even contradict it, denying you saw what appeared to be before you just then. So, your experience fails to harmonize with other 'experience,' in a sense broad enough to include others' testimony. But that is not the kind of harmonizing that counts. We are interested in the harmony or lack thereof obtaining between (possible) "perceptual" experiences. For there to be a lack of harmony, the butterfly experience has to belong to a set of perceptual experiences containing at least one experience that is inconsistent with the rest but for which there is no possible subsequent resolution.

Let us think about the case in greater detail. If, for instance, as the butterfly leaves your field of vision you suddenly take interest in it and act to visually relocate it, you will not succeed, given that the hallucination cut off at the moment the butterfly left your field of vision. Does that in any genuinely perceptual sense break the harmony of your experience? That depends, first, on whether failing to perceive something in some cases involves perceiving an absence. I am not certain that it does. Obviously, if we do not perceive absences, there cannot be any inconsistency, and neither a loss of harmony. Let us grant that we do sometimes perceive absences anyway and see what comes of it. Returning to our butterfly case, you have tried to perceptually advert to the now out-of-view butterfly but it is nowhere to be found. You perceive its absence. Is there an inconsistency here? Not any more than in other cases where you perceive absence. There is no inconsistency, for instance, when I look for my keys and find they are missing. I have simply lost track of them. I have not misperceived anything. 
The keys, however, will turn up again, whereas the butterfly will not. Is that relevant to your perceptual experience? Again, the answer is not obvious. It is only relevant if harmoniously experiencing something always requires further possible reidentification. That is a hefty demand to place on perceptual experience. In fact, there is good reason to doubt that reidentification must be possible. Just like hallucinated objects, really existing objects do not last forever. Therefore, a demand for reidentification ad infinitum instead of guaranteeing harmony actually opens up the possibility of disharmony vis-à-vis veridically perceived objects. For instance, in the event that a previously perceived, really existing object goes out of existence and you subsequently perceive its absence.

To avoid the difficulty, you could tack on a further condition to that demand. It could be stipulated that you must be able to reidentify the object up until the moment of its destruction. Even that may not do the trick, though. After all, it is not necessarily the case that you can always perceive an object's destruction. A virtually incomprehensible number of objects have likely expired in conditions inhospitable to the exercise of our perceptual capacities. The same fate very well may await various objects that we encounter perceptually in the course of our lives.

It looks like even if we help ourselves to increasingly contentious assumptions about perceptual experience, it will not be enough to show that there is any lack of harmony in your perceptual experience after the butterfly episode. To press the point further, allow me to be similarly liberal with our butterfly hallucination case. We could modify the example to meet the condition of re-identification, whether ad infinitum or ad destructionem. All you have to do is imagine a more persistent hallucinatory condition generating a more elaborate hallucination. Sartre's crabs, after all, are supposed to have followed him around for a brief period of his life and not merely for seconds, minutes, hours, or even days. If we are allowing for the possibility of perfect hallucinations at all, I do not see what would stop us from allowing further embellishment of the idea along these lines.

Going even further, we could do one better by supposing the hallucination to be "veridical." That is, we could imagine that you hallucinate a butterfly as though it were located where there is in fact a butterfly and experience the hallucinated butterfly in a way that accords with what you would perceive of the real butterfly. To make this example fully work, we would need to assume that you are familiar with the real butterfly—-maybe you hatch them as a hobby-and are hallucinating that same butterfly. That is because, as Smith stresses, Husserl takes perception to identify and re-identify particulars as particulars, ${ }^{49}$ so a "veridical" hallucination must likewise pick out the particular. In that iteration, inconsistency and breach of harmony are difficult if not impossible to fathom.

\subsection{Systems of Possible Perceptual Experience That Contain Hallucination}

The veridical hallucination case is interesting for a further reason. It not only provides an example of a harmonious hallucination, a possibility Smith's account is supposed to rule out in principle, but also serves as a counterexample to the general claim that, necessarily, a hallucinatory experience cannot belong to a

${ }^{49}$ Smith, "Husserl and Externalism," 324-27. 
system of possible veridical perceptions directed upon a real object. ${ }^{50}$ That is, there is supposed to be zero overlap between a system of possible experiences pertaining to a really existing and one pertaining to a hallucinated object. The veridically hallucinated butterfly appears to be inconsistent with that claim. It fits seamlessly into the system of non-hallucinatory perceptual experiences identifying and reidentifying that entity, the real butterfly.

Hopp anticipates this objection and considers several lines of reply. ${ }^{51}$ How to reply depends on how exactly the hallucinatory condition is understood. Hopp entertains two possibilities. In one, a mad scientist is responsible for the hallucination and designs it to track the scene before you flawlessly. In my example, we would imagine the mad scientist to be playing a trick on you (an oddly pointless one, but this is a mad scientist we are talking about) where you suffer a butterfly hallucination that maps on perfectly to the experience you are having of that very same butterfly. In a second version, the mad scientist has created a setup that can generate such veridical hallucinations in you, but does not operate it with that intent, only accidentally flipping it on with that effect occasionally.

In response to the first, Hopp suggests that the hallucination is not really a hallucination.$^{52}$ The idea is that the reliable causal link between the butterfly and your nervous system in this case ensures that your experience can play the same role as an ordinary perceptual experience. If that is so, it is natural to think there is no important difference between them. But there are non-trivial differences between the two experiences. Your visual system is not properly functioning. The hallucinated object is not the proximate cause of your experience, and it is not clear whether we should say the episode has any "stimulus" at all, in the usual sense (i.e. something affecting your sensory transducers, your retinae). The net result of these observations is not favorable to Smith and Hopp.

After all, the aim of the disjunctivist is to emphasize how hallucination differs in kind from perceptual experience proper. And the point of the counterexample is to show that the two are of the same kind and resemble one another in relevant respects. But Hopp's response to the possibility of a hallucination resembling veridical perceptual experience, to the point of also being veridical, is to highlight further, deeper resemblances. He takes this to show that the veridical hallucination is no hallucination at all. But he cannot-and does not explicitly-deny the manifest overlap between the veridical and non-veridical hallucination. Think about it this way. Assume there is a fundamental commonality between non-veridical and veridical instances of hallucination and that, further, as Hopp says, that a similar commonality exists between veridical hallucination and veridical perceptual experience. It is tempting to infer that the commonality must also hold between the non-veridical hallucination and the veridical perceptual experience. A more substantive argument separating veridical and non-veridical cases of hallucination is needed. In lieu of that, Hopp's response reads like a tacit concession, since the entire point of the objection is to show the underlying commonality between hallucination and veridical perceptual experience.

\footnotetext{
${ }^{50}$ Smith, "Husserl and Externalism," 330-3 I; and Hopp, Perception and Knowledge, I 84-85.

${ }^{51}$ Hopp, Perception and Knowledge, I 85-88.

${ }^{52}$ Hopp, Perception and Knowledge, I 8 5-86.
} 
As for the second version of the mad scientist case, where it is only by accident that you are caused to suffer hallucination, Hopp adjusts Smith's proposed reading to neutralize the threat of the counterexample. Adapting an idea from Ernest Sosa, ${ }^{53}$ Hopp suggests that, to qualify as genuinely perceptual, an experience must meet the condition that "in situations not too remote from the actual one, had things been different, my experiences would have been correspondingly different as well. ${ }^{{ }^{54}}$ Call this the 'safety condition.' To meet it, counterfactual variations in your experiential state must map on to counterfactual variations in your perceptual surroundings. While veridical perceptual experiences meet the safety condition, the veridical hallucination we are currently reflecting on does not. If the perceptual circumstances had been different and the mad scientist hit the same button, the hallucination would not have been veridical, because it would have been the same as it is in the situation we are imagining to be the real one.

Now, think for a moment about the purpose of the safety condition outside of the present setting. It is part of a story about how to differentiate knowledge from true belief, and accidentally true belief, in particular. It offers a criterion for a certain kind of success, namely, of epistemic success. It is clear what we gain by adopting the safety condition in the case of knowledge, because it is settled that knowledge is a success state and the point is to figure out what is distinctive about it as a success state. In our case, we are trying to determine the nature of perceptual experience. Yet, disagreement among parties involved in the discussion runs deep. One party to the debate, the conjunctivist, holds that both veridical and non-veridical experiences qualify as perceptual in the same fundamental respect, a respect that obviously does not require perceptual experience as such to be veridical. It is only the other party, the disjunctivist, who is inclined to say about perceptual experience something that might ground the analogy with Sosa's safety condition, since for the disjunctivist some forms of perceptual experience are inherently successful (i.e. veridical).

In the case of perception, then, it is not an appropriate dialectical starting point to grant that (some) perceptual experience is successful by nature. Hopp may be right that the safety condition is a good guide for drawing some kind of useful distinction between hallucinatory and perceptual experiences more generally. But he does not give any straightforward guidance, apart from bare assertion, about the nature of the distinction that would support treating it as a distinction cutting to the core of perceptual experience. Meeting the safety condition does not seem fundamental in the right sense (see section 4 below). It does not account for characteristic features of our experience. For the safety condition to do the relevant work, Hopp would need to explain why it is that veridical perceptual experience and hallucination appear to have all of the same phenomenally discernable features, yet the former has them in virtue of meeting the safety condition while the latter has them for some other reason.

Further, the point of the safety condition in the epistemological context is to account for the distinction between knowledge and accidentally true belief, that is, to differentiate two kinds of successful states, both successful qua accurate, by

\footnotetext{
${ }^{53}$ See Ernest Sosa, A Virtue Epistemology.

${ }^{54}$ Hopp, Perception and Knowledge, I 86.
} 
accounting for an additional, distinctive kind of success that goes into knowledge and not accidentally true belief, giving the former a special dignity or warrant for its possessor. But accidentally true belief is not deficient in quite the way that a hallucinatory experience is. And it is not ruled out that accidentally true belief and knowledge are in an important respect of the same fundamental nature, as beliefs. The analogy between perceptual experience and knowledge is not as clear cut as Hopp implies.

Absent details motivating and explaining the importation of the safety condition to sort out the relation between hallucination and perceptual experience, Hopp's appeal to the safety condition seems ad hoc and his inference from the applicability of the safety condition to the conclusion that veridical perceptual experience and veridical hallucination differ in their fundamental natures is a non sequitur.

\subsection{Systems of Possible Perceptual Experience That Fail to Harmonize}

Smith's reading of Husserl apparently grants that illusory and veridical perceptual experience are fundamentally the same sort of experience. It allows for that only on condition that the total system of perceptual experiences of a given really existing object experienced in an illusory way contains a possible experience correcting the illusory one. Smith's view of the line drawn between veridical perception, on the one hand, and hallucination, on the other, now faces an objection not unlike the one Overgaard lodges against Staiti's view of that demarcation. For Staiti, it is the actual future unmasking that marks a hallucination (or illusion) as such, whereas, for Smith, it is a possible unmasking. As Overgaard suggests we do for Staiti, here, too, we should question whether the quality of an experience as illusory or hallucinatory depends on how things stand with other perceptual experiences.

I will return to that question at a greater level of generality below (section 3.5). For now, let us just focus on the possibility of persistent illusion as a counterexample to the idea that belonging to a system of possible experiences that is ultimately harmonious is indicative of veridical perceptual experience's fundamental nature. If there are intractable illusions that cannot be resolved perceptually, then it follows that systems of veridical perceptual experience are not necessarily harmonious like Smith claims. More importantly, if that is true, it also follows that belonging to a harmonious system of possible experiences cannot be used to distinguish hallucinatory and veridical perceptual experience, since some (partly) veridical perceptual experiences, those involving persistent illusions, will not belong to corresponding ultimately harmonious systems.

The sort of intractable illusion I have in mind is nicely illustrated by the MüllerLyer illusion. (Examples could be multiplied.) There is no possible resolution of it within perceptual experience. Because the classic Müller-Lyer is a depiction, it will help to imagine it in modified form. To make the point pertinent to this objection, it must be possible to misperceive an object as having some property that it does not but not possible to correct that misperception. So, let us imagine a case where not a depiction but a real-life, solid, three-dimensional Müller-Lyer setup stands before you. You, of course, misperceive the two objects as differing in the length of their long, horizontal components. There is no way, not within the realm of perceptual experience, to unmask the illusion. 
You might think that correction is possible here. After all, you only misperceive the horizontal length of the objects when they are presented in certain way. There is no reason to think you could not correctly perceive each object when viewed separately. Nevertheless, the illusion does persist. True, you can perceptually resolve the horizontal lengths of the lines taken individually. But that does not entirely resolve the illusion. You still cannot correctly perceive their relative length. In the illusion, part of what you misperceive is precisely their relative length. It looks like one is longer than another. It is not absolute length that stands out here. And it turns out that however you arrange the two objects relative to one another (if we take their depictions as reliable guides), the illusion persists.

Luckily, we can use what we learn from perceiving the two objects separately that they are in fact the same length. You could even interpose a ruler between them showing their sameness of length. But that revelation is a feat of judgment, not perception. With the ruler present, you perceive each object as the same length as the ruler, but not as the same length as each other. The logical relations that hold between our separately formed judgments based on that experience are not written into the experience itself. We may perceive one thing as "the same length as" another. Still, our perceptual capacities are not equipped to take a further step and exploit the transitivity of that relation, which is necessary for resolving the illusion. In other words, the system of perceptual experiences for each of the Müller-Lyer objects contains inconsistencies that are unresolvable.

\subsection{A Problematic Conception of Hallucination}

So far, the objections I have presented have rested on counterexamples designed to illustrate that the line Smith draws between hallucination and veridical perception does not represent any real, fundamental difference between the two. That suggests it is worth giving a closer look to just how Smith draws that line. While Smith is careful in setting out the notion of veridical perceptual experience, the same cannot be said of his remarks on hallucination. These are largely negative characterizations. One thing Smith is clear about is that hallucinations belong to systems of experience that are not ultimately harmonious and that do not contain any veridical perceptual experiences. Pressing for clarification reveals that the understanding of hallucination Smith attributes to Husserl is untenable.

We can make headway by modeling our conception of hallucination in part on that of veridical perception. To be ultimately harmonious, a system of experience must contain all and only experiences of one particular object in such a way that for any antecedent experience mischaracterizing that object there is some possible subsequent experience correctly conveying what that object is like in the relevant respect. Presumably, ultimately unharmonious systems, those containing hallucinatory experience, likewise bear on one and only one object, the underlying assumption being that we individuate systems of experience based on their object. ${ }^{55}$ Assuming, further, that the hallucination is a hallucination of some object, then the system containing the hallucinatory experience in question will contain all possible experiences of that hallucinated object. The failure to harmonize, then, will be among those experiences.

${ }^{55}$ Smith, "Husserl and Externalism," 330. 
564 JOURNAL OF THE HISTORY OF PHILOSOPHY $58: 3$ JULY 2020

What will it mean for them to fail to harmonize? It is not sufficient that the experiences all mischaracterize their object, let us say, as being present before you at the various times and places you appear to experience it, and that none of them get it right. (Of course, except in the unlikely event of veridical hallucination, none of them will get it right.) You might think it is enough for an experience to count as a hallucination if it presents you with an object that is not in fact before you. That will not do, however, because the lack of harmony would be between the experience (i.e. every member of the system) and the world. What we are looking for is a lack of harmony within experience or among experiences.

Smith sheds light on how that might work when he says that, "if the object of some experience is unreal, there is some possible experience of that object in which its unreality is exposed. ${ }^{\circ 56}$ Set aside the problem represented by the counterexample I presented against this idea above and see if we can clear up exactly what it would mean for a hallucinated object to be unmasked, for the hallucinatory object to be exposed as such. Whatever the unmasking consists of, it must feature in the experience itself, somehow, and must concern experience only insofar as it bears on a given object of experience. Any disharmony, whatever it would amount to, between that object and other perceptibilia is immaterial. ${ }^{57}$ Note that, for two reasons, the termination of the hallucination does not qualify as unmasking in the relevant sense.

First, as already noted, it is not written into your experience of an object how long it will be around and under what circumstances it will or will not persist. You might think that exposure to objects that have a certain temporal profile (i.e. roughly, as being something that typically has such-and-such, e.g. relatively permanent or fleeting, duration) will produce expectations that they will behave consistently with that temporal profile. ${ }^{58}$ Thus, you will expect smoke, shadows, specular highlights, etc., to have a temporal profile much different from, say, boulders, buildings, and the like. And, maybe, if you are a grocery store clerk responsible for stocking shelves, you may have fine-tuned expectations about what items will disappear with what frequency. To generate conflict, this temporal profile must be captured in the content or sense of the object in question, so that it is experienced as having such-and-such a temporal profile. I doubt that this is so.

It might be said that we experience a violation of expectations when something behaves out of line with its typical temporal profile, and that this is reason enough to attribute the relevant temporal content to perceptual experience. That is a weak phenomenal basis for such a substantive claim. It could just as well be that the expectations are cognitive in nature and not perceptual. That even seems likely, as something more straightforwardly thought-like (but maybe still sub-doxastic) seems better suited to gauging different types of objects' relative durability and tracking particular objects' position in their type-bound temporal allotment. So, it is unlikely that we experience things as having any particular temporal profile so as to enable the sort of inconsistency needed on Smith's account. If we did

\footnotetext{
${ }^{56}$ Smith, "Husserl and Externalism," 329.

${ }^{57}$ Smith, "Husserl and Externalism," 330.

${ }^{58} \mathrm{~A}$ reply in this vein was suggested to me by an anonymous reviewer, to whom I am grateful for the idea.
} 
experience them that way, moreover, that would still be insufficient to generate the inconsistency. As I will explain in a moment, experiencing something as behaving in an unusual way (e.g. with respect to its temporal profile) need not involve any kind of conflict.

Second, in the event that you no longer experience the hallucinated object, no possible inconsistency can crop up because disharmony, as we have just observed, can arise only among experiences of one and the same object. Once you have stopped hallucinating, necessarily, you are no longer experiencing the hallucinated object and, thus, your post-hallucination experience cannot stand in the right kind of relation with your pre-hallucination experience to create disharmony.

There has to be something about your experience of the hallucinated object that betrays its hallucinatory character. The hallucinated object must unmask itself. Or, more precisely, there must be some possible perceptual experience of it that unmasks it. Husserl gives a clue at how we might develop this idea. He characterizes hallucination as experience that "deviates from the usual content," so that "we have a conflict between what the appearing object requires in the way of supplements or moments and what it actually offers in the mode of appearance. ${ }^{י 99}$ That is because certain "moments belonging to the appearance demand, empirically, certain other moments, certain supplements, which are missing here." ${ }^{60}$ To illustrate, Husserl has us imagine we are confronted experientially with a "half person." We could imagine, similarly, a hallucinated object, any medium-sized dry good, behaving in non-standard ways, maybe fading somewhat (becoming semi-transparent), passing through solid objects, paying no heed to the pull of gravity, etc., as we envision ghosts doing.

In these cases, something is off about the experienced object. The half person is recognized as a person. But people, as we usually experience them, look quite different from this one. Our experience "demands" something of this being that it does not deliver. Let us suppose, further, that something like that is true in other cases of hallucination. We can then generalize and say that a hallucinated object unmasks itself by failing to exhibit, possibly only in subsequent experience, the right experientially detectable traits. Given the type of thing it appears to be (or appeared to have been), it ought to appear some way that it does not. The same goes for illusions. In Husserl's favorite example, you misperceive a mannequin as a person, and this becomes apparent when the mannequin fails to show telltale signs of being a person like moving or making expressive gestures.

The proposal under consideration, then, is that an experience is hallucinatory if it belongs to a system of possible experiences containing at least one other member that unmasks the hallucinatory object as not behaving as objects of its kind standardly do. This suggestion has shortcomings that are significant enough to warrant its rejection. To begin, it is not clear that this conception of hallucination does what it sets out to do. The unmasking in question involves a conflict between experiences of a particular object and exemplary or normal experiences of objects of its kind rather than between other experiences of that same particular object.

\footnotetext{
${ }^{59}$ Husserl, Hua 23:I33/Phantasy, I47n43.

${ }^{60}$ Husserl, Hua 23:I46/Phantasy, I7 I.
} 
Given this, if the encounter with the half person indicates anything, it is that the perceived entity is non-standard, atypical in some respect. It does not indicate anything about the experience. Many veridical perceptual experiences are of nonstandard or unusual items and do not for that reason qualify as hallucinatory (or illusory) in the relevant sense.

It will not help if, as might be suggested at this point, we require the unmasking to involve conflict between experiences of the hallucinated object, so that, perhaps, you experience a half person that once was a whole person. There is a conflict in this case between what you experience now and what you (could) have experienced previously. The violation of expectations or, more importantly, the conflict that this violation signals, however, bears no relevant difference from that involved when the object experienced has simply undergone change, transforming from an ordinary token of its type to one deviating from that type. The point is that, by this standard, many, if not all, systems of possible perception will count as ultimately unharmonious, given that the object their constituent experiences all identify can undergo the relevant sort of deviation from the norm (relative to a particular object), thus triggering the type of uncanny experience Husserl describes.

Ultimately, the suggestion that we understand disharmony this way presents neither a necessary nor sufficient condition for hallucination. I have just indicated that plenty of ordinary episodes of veridical perceptual experience will meet this criterion for inconsistency. So, meeting the criterion is not enough. It is not sufficient to guarantee that a given experience is a hallucination (or illusion). It would likewise be a stretch to suppose that exhibiting this kind of inconsistency is necessary for an experience to count as a hallucination. That is obviously not true. People have hallucinations (or can have hallucinations), I take it, that are not inconsistent in this way.

However, to keep with Smith's general approach, the idea would have to be that for any given hallucinated object, there is some possible experience of it that would engender the relevant kind of inconsistency. That is, the criterion is meant to apply to systems of possible experience, not to experiences taken individually. If that is true, it is trivially true. Supposing we are not taking on toxic metaphysical baggage, the hallucinated object could undergo the pertinent sort of "change," deviating from its apparent kind or from how it once seemed to be, and be accompanied (necessarily, presumably) by corresponding hallucinatory experiences. If that can be said of hallucinated objects, surely an analogous claim applies equally to systems of possible veridical perceptual experience. So, the price of offering this as a necessary condition is triviality. The value of this as a criterion for disharmony lies solely in what it does to help us see how systems of hallucinatory and veridical perceptual experience differ. Unmasking, as we are currently thinking of it, does not do that.

\subsection{Failure to Get to the Fundamental Nature of Perceptual Experience and Hallucination}

Set aside the preceding objections. Assume, for the sake of argument, that systems of possible perceptual experience are all ultimately harmonious, that systems of 
hallucinatory experience are ultimately unharmonious, that no system of possible experiences contains both perceptual and hallucinatory experience, and that there is nothing inherently problematic about Smith's understanding of hallucination as belonging to ultimately unharmonious systems of experience. Still, I have the lingering suspicion that Smith's account does not show that hallucination and veridical perceptual experience fundamentally differ in kind. What strikes me as questionable is how the fundamental nature of the two kinds of perceptual experience is determined.

To determine an experience's fundamental kind, Smith relies crucially on the relation it stands in to other possible experiences as part of a system of experiences containing them, where they all share certain features and the system itself has certain properties. In the case of perception, the experience must belong to a system whose members all identify the same object as the same and where the system itself ultimately harmonizes, that is, contains for any antecedent misconstrual of the system's target object a subsequent experience correctly construing it in the relevant respect. In the case of hallucination, an experience is hallucinatory if it belongs to a system of possible experiences that is ultimately unharmonious and so contains some possible experience that unmasks the hallucinated object as unreal.

If that is all true, then we have a reliable guide for telling apart perceptual experiences and hallucinations. And it would be true that all perceptual experiences and no hallucinations are object-involving. We can even say that they are different kinds of experience, because there is something that is true of all and only the one sort but not the other and vice versa. But are they fundamentally different kinds of experience? Do they have different natures? What suggests to me that we should answer in the negative to those questions is that, despite the differences Smith mentions, a token perceptual experience and a token hallucination may have all the same kinds of features, differing only in the relation they happen to stand in with respect to other experiences, and other possible experiences, at that.

Let us consider the evidence in favor of there being a common structure shared by perceptual experiences and hallucinations as Husserl thinks of them. First, it is well known that Husserl attributes to both the feature of "presence in the flesh" or "presence in person" (Leibhaftigkeit): "To perceive a house means to have the consciousness ... of a house standing here in the flesh. How matters stand with the so-called existence of the house ... - about all that nothing is said." ${ }^{\prime 1}$ This is Husserl's way of highlighting the directness and immediacy that is distinctive of how objects are presented in perceptual experience-and hallucination-but not in memory, imagination, and thought more generally. Perception and hallucination alike present objects as present in the flesh and no other kind of mental state has this feature. That is a deep commonality in their fundamental nature.

A number of further commonalities are apparent in Husserl's discussion of "modalization." ${ }^{2}$ Husserl thinks of perceptual experiences as involving a "mode." The default mode is a belief-like quality that he often refers to as a kind of certainty.

\footnotetext{
${ }^{61}$ Husserl, Hua I6:I2-I3/Thing and Space, I4-I6; Hua 3:97/Ideas I, IO2; Hua 3686-87; and Hua 38:I I.

${ }^{62} \mathrm{Husserl}$ Experience and Judgment, 87-IOI; and Hua I I:2 5-64/Passive Synthesis, 63-105.
} 
Modalization occurs when some stretch of perceptual experience switches modes, for example, from certainty to doubt or possibility. For instance, you might see what looks to you like a person, and in the course of perceiving them it may happen that your perceptual uncertainty erodes, turning into uncertainty or doubt as you waver between perceiving what is before you as a person and as a mannequin. ${ }^{63}$ Husserl routinely describes episodes with that profile as modifications. These modifications are precisely the stuff that harmonization or failure to harmonize is made of, as modalization occurs not only within continuous stretches of perceptual experience, but also between distinct token perceptual experiences.

When an illusion is corrected or a hallucination is unmasked, that is an instance of modalization. ${ }^{64}$ How, then, is thinking about modalization supposed to bring out the commonalities between perception and hallucination? Well, illusions and, by extension, hallucinations are understood to be modifications of perceptual experience. That is, it is not as if there are heterogeneous perceptual and hallucinatory elements mixed up in experience or that perceptual experience temporarily breaks off during hallucination. Rather, there is continuity. Husserl thinks of perceptual experiences as interacting with illusions and hallucinations in a way that just is not possible with any other kind of experience. It is natural to think that is because of the shared nature of veridical and non-veridical experience and the diverging nature of perceptual experience, veridical or not, and, for instance, what I learn from another's testimony.

Husserl enumerates several commonalities between the good case (veridical perception) and the bad case (illusion or hallucination). They both involve sense data, even the very same sense data, and they both involve an apprehension, interpretation, or construal of those sense data, by virtue of which the sense data come to present mind-transcendent objects. ${ }^{65}$ From what we have seen earlier, it is evident that they have modes, and can have the same mode (e.g. certainty or doubt) ${ }^{66}$ And, importantly, this certainty is distinctively perceptual and not reducible, for Husserl, to belief, thus being common to perception and hallucination, but not thought. Finally, perceptual experience and hallucination can share not only the very same (i.e. type-identical) sense data, but even (some) of their content, that is, what the sense data function to present or what the object of experience is taken to be in that experience. ${ }^{67}$

None of what Smith (or Hopp or Overgaard) says includes a denial of any of those commonalities. I think they are sufficient for us to lump together perceptual experiences and hallucinations into a common kind as fundamentally the same. Even if we concede-which I do not actually recommend, based on the arguments I presented above-that there is something like Smith describes that all hallucinations have in common but that veridical perceptual experiences lack and vice versa, I fail to see why that is a difference that makes a difference

\footnotetext{
${ }^{63}$ Husserl, Hua I I:30-33/Passive Synthesis, 69-72.

${ }^{64}$ Husserl, Hua 9:43-44, I 27, I4 I/ Phenomenological Psychology, 59-60, I65, I 84; and Hua I I:33-36/ Passive Synthesis, $7 \mathrm{I}-75$.

${ }^{65}$ Husserl, Hua 9:I 27/ Phenomenological Psychology, I 65; and Hua I I:34/Passive Synthesis, 73.

${ }^{66}$ Husserl, Hua 9: I 4 I / Phenomenological Psychology, I 84; and Hua I I:33 / Passive Synthesis, 72.

${ }^{67}$ Husserl, Hua I I:34/ Passive Synthesis, 73.
} 
or that should outweigh considerations about the distinctive structural features they both share. The commonalities I have just related from Husserl's account consist of shared intrinsic features of the experiences. What separates perceptual experience and hallucination, for Smith, is not any kind of intrinsic feature, but their respective relational properties, that is, the relations they bear to systems of possible experience centered on particular objects.

If you want to know what something's nature is, surely you want to know about its distinctive intrinsic properties, and not its relational properties, unless the latter include distinctive internal relations, which, in the end, are grounded in and can be chalked up to intrinsic properties anyway. But the relational properties Smith appeals to are grounded in intrinsic properties-namely, the experiences' content, especially the core of it that enables reference to a particular object-that are in fact shared by perceptual experiences and hallucinations. It follows, I submit, that Smith's attempt to piece together a Husserlian disjunctivism fails because he has not given us an account of the fundamental nature of perceptual experience and hallucination and that the evidence I have presented from Husserl strongly favors a conjunctive reading of his view of perception and hallucination.

\section{A C O NJUNGTIVE READING OF H US SERL}

The foregoing discussion lends some at least prima facie support for a conjunctive reading of Husserl. I have suggested that the alternative readings are either seriously underdeveloped, like the illusionist reading (section 3), or face numerous objections, like Smith's disjunctivist reading (section 4 ). I also, in response to Smith's disjunctive reading, presented evidence in favor of a conjunctive reading by laying out some common core features belonging to both perceptual experience and hallucination as Husserl understands them (section 3.5). That, I think, goes a long way in response to what I would call 'Overgaard's Challenge.' Overgaard's Challenge, directed to proponents of conjunctive readings of Husserl (and to Romano, ${ }^{68}$ in particular), is to locate a textual basis in Husserl's writings for something more than the claim that, as far as the subject of experience can tell, any given experience could turn out to be a hallucination. The latter is only a claim about our ability to tell apart perceptual experience and hallucination and not yet a claim about their fundamental nature.$^{69}$ In closing, I will offer what I take to be compelling support for a conjunctive reading of Husserl that meets this challenge.

A first line of response to Overgaard's Challenge arises from further reflection on the matter of indiscriminability. Suppose you are looking at two objects, two medium-sized dry goods that look exactly alike to you. The fact that you cannot tell them apart obviously does not mean they are the same. Your experience does not necessarily disclose their nature, or, at least, not all of it. Husserl's example of the mannequin misperceived as a person shows that. The two have very different natures despite looking (we imagine) identical. So, in many cases it is a stretch to infer from indiscriminability to sameness of nature. But are the experiences we are interested in like that? Or, would Husserl think of them that way? I am not so sure.

\footnotetext{
${ }^{68}$ See Romano, "Must Phenomenology Remain Cartesian?"

${ }^{69}$ Overgaard, "Perceptual Error, Conjunctivism, and Husserl," I 2-I3.
} 
Husserl is of the view that, at least when attended to with careful reflection, all there is to know about a given mental state's nature can be discerned by having and reflecting on exemplars of that kind of mental state. This is how he typically proceeds in his work and what he recommends in describing his method of eidetic variation. ${ }^{70}$ That approach is premised on his view that mental phenomena, unlike mind-transcendent phenomena, can be "adequately" or "absolutely" given. ${ }^{71}$ Mental states have no hidden interior or occluded parts, everything is (potentially) open to view. That is because, Husserl claims, "the sort of being which belongs to the mental process [Erlebnis] is such that the latter is essentially capable of being perceived in reflection." 72

Despite the boldness of that last quoted remark, Husserl acknowledges that there are limits to our reflective powers that make determining the nature of our mental life a less than straightforward affair. ${ }^{73}$ Reflection is like "external perception' in that our awareness, by virtue of its foreground/background structure (both at a given moment and diachronically) may preclude us from attending to a mental phenomenon exhaustively. What falls into our attentive regard is not all that is available to reflection. Husserl is nevertheless emphatic that, analogous limitations notwithstanding, the mental is available in a distinctive and privileged way in comparison to the physical.

On the one hand, noetic aspects of experience-the recessive or largely unnoticed characteristics of experience that account for our intentional directedness toward things - are available as proper parts of experience and of reflection on it. ${ }^{74}$ On the other hand, noematic aspects-experienced objects' modes of appearing, what they are presented as being — are available as necessary "correlates" of noetic aspects. ${ }^{75}$ Noematic aspects are grounded in noetic ones, the latter involving a kind of "sense bestowal" (Sinngebung), and, presumably thanks to that grounding, claims about the noema can always be justified by reflection, for instance, on "the mental process of perceiving," so that the noema is understood "just as it is offered to us when we inquire purely into this mental process itself." 76 Thus, the "mental process" (Erlebnis), the intrinsically conscious experience with its internal, noetic components, is for the noema the proper locus for reflection on its noematic correlates.

Further, setting aside the primacy of the mental in reflection and the standard of "adequacy" that it alone meets, Husserl holds generally that first-hand experience is indispensable for revealing things' natures, what is true of them universally or by essence. ${ }^{77}$ So, as difficult as it may be to ascertain the natures of veridical perceptual experience and hallucination, we have every reason to think that such differences, if they exist, can be made manifest in experience.

If that is right, then the only way to discover the nature of hallucination or perceptual experience is to have those experiences and reflect on relevant

\footnotetext{
${ }^{70}$ Husserl, Hua 9:53-60/Phenomenological Psychology, 72-8 I.

${ }^{71}$ Husserl, Hua 3:73-79/Ideas I, 86-72.

${ }^{72}$ Husserl, Hua 3:84/Ideas I, 99; and Zahavi, "Phenomenology of Reflection," I77-90.

${ }^{73} \mathrm{I}$ am grateful to the anonymous reviewer who recommended consideration of this issue.

${ }^{74}$ Husserl, Hua 3:82-83/Ideas I, 97-88; and Hua 9:I I 7 / Phenomenological Psychology, I 52.

${ }^{75}$ Husserl, Hua 3:I 87-88/Ideas I, 220-2 I.

${ }^{76}$ Husserl, Hua 3:I 82/Ideas I, 2 I 4.

${ }^{77}$ Husserl, Hua 9:74/ Phenomenological Psychology, 98-99.
} 
exemplars. Then either hallucination has some distinctive nature other than that of veridical perceptual experience and can always in principle be distinguished from veridical perceptual experience or it does not have a peculiar nature and cannot necessarily be distinguished in that way. Proponents of conjunctive and disjunctive readings alike acknowledge Husserl's admission of the possibility that hallucination may be indistinguishable from veridical perceptual experience. ${ }^{78}$ Husserl's remarks to that effect are too numerous and too unambiguous for this to be a point of contention. ${ }^{79}$ So, it is far from implausible to think that, taken with the background ideas just mentioned, such comments commit Husserl to a form of conjunctivism.

What I have just said is borne out by an examination of Husserl's comments on hallucination and perceptual experience. Consider the sort of passage that tempts readers like Romano to interpret Husserl as a conjunctivist:

If I perceive a house, then, . . . however things may stand with this causal relation and whether or not there is something to be said against it, it can in any case be made evident that a relationship of consciousness is contained in the lived experience of perceiving itself, and indeed a relation to the house perceived in it itself. It can happen that later on I become correctly convinced that I have fallen victim to an illusion. But previously I did have purely the consciousness "house-existing-there"; descriptively it is no different from any other perceiving. Of course there can be no talk of external-internal psychophysical causality if the house is a mere hallucination. But it is clear that the momentary lived experience is in itself not only a subjective lived experiencing but precisely a perceiving of this house. Therefore, descriptively, the object-relation belongs to the lived experiencing, whether the object actually exists or not. ${ }^{80}$

Here we find Husserl clearly giving voice to the idea that hallucination may be indistinguishable from veridical perceptual experience. Overgaard's Challenge is to identify something more substantial, namely, a claim "about the metaphysical nature of veridical perceptual experiences." ${ }^{11}$ The point I want to make in quoting this passage is that there is no clear line for Husserl between comparing what two experiences are like to have and what all goes into their metaphysical nature. This is apparent from his use of the term 'descriptive' and its cognates, which shows up in other passages expressing the same idea, such as the one Overgaard cites. ${ }^{82}$

To contemporary ears, Husserl's remark that "descriptively, the object-relation belongs to the lived experiencing, whether the object actually exists or not" may sound like a report on what the experience is like, a report only concerning its phenomenal character and thus falling far short of being a claim about its fundamental nature. But that is not at all how it should be understood. ${ }^{83}$

In speaking of an experience's descriptive features, Husserl means precisely to identify its fundamental nature, not merely to convey only certain superficial

\footnotetext{
${ }^{78}$ See Romano, "Must Phenomenology Remain Cartesian?” and Overgaard, "Perceptual Error, Conjunctivism, and Husserl," respectively.

${ }^{79}$ Husserl, Hua 38:I $33 ;$ LI 2:83, I 37; Hua I 6: I 2 / Thing and Space, I 4; Hua 9:22-23/Phenomenological Psychology, 3 I-32; Hua I I:36-37/Passive Synthesis, 376-77; and Hua 36:86-87.

${ }^{80}$ Husserl, Hua 9:22-23/Phenomenological Psychology, 3 I-32.

${ }^{81}$ Overgaard, "Perceptual Error, Conjunctivism, and Husserl," I3.

${ }^{82}$ Husserl, $L I$ 2:83.

${ }^{83}$ Husserl, Hua 9:23/ Phenomenological Psychology, 32.
} 
572 JOURNAL OF THE HISTORY OF PHILOSOPHY $58: 3$ JULY 2020 aspects of it. When embarking upon phenomenological description of our experiences, he says, "We must ideate universal essences and essential connections in such experiences." ${ }^{4}$ Phenomenology, as a descriptive enterprise, renders accessible "Whatever can be apprehended eidetically in pure intuition as belonging to reduced mental processes, either as a really inherent component part or as an intentional correlate of the latter." 85 So, when Husserl says two experiences are descriptively the same, that does not just mean they are subjectively indistinguishable. If the description is properly carried out, then they also have the same really inherent component parts and intentional correlates, to borrow Husserl's idiom.

True, Husserl's view leaves room for the possibility that there is an undetected difference (though not for an undetectable difference). After all, I noted, Husserl concedes that our reflective regard cannot catch everything of significance in its net all at once. However, Husserl's own analyses point to convergences rather than divergences in nature between veridical perceptual experience and hallucination. (On that score, recall some of the points, e.g. about modalization discussed earlier in section 3.5. More on that in a moment.) Given that, the mere possibility that some difference could turn up does mean that we have to be open to that eventuality, but hardly means that we should significantly discount the commonalities Husserl highlights. The burden lies on the shoulders of the Husserlian disjunctivist to identify a relevant (i.e. fundamental) difference, whether recorded in Husserl's own ruminations on the matter or found in our own reflection.

I think that this first line of response is sufficient to dispose of Overgaard's Challenge. Nevertheless, to seal the deal, I want to return to the argument I made earlier, in addressing Smith's reading of Husserl, that Husserl's comments on perceptual experience and hallucination often present the two in terms of their fundamental commonalities, which supports a conjunctive reading (section 3.5). In reply, it might be said that disjunctivism is consistent with there being commonalities between veridical perception and hallucination. In that case, it will not suffice to rule out disjunctivism just to identify features shared by the two kinds of experience.

If that is right, there are nevertheless constraints on those commonalities. Some features can be shared by veridical perceptual experiences and hallucinations, but not all features can. So, we need a way to differentiate those features. That is not a point we can dwell on at length here. In lieu of that, let us work with Heather Logue's proposal:

according to disjunctivism, the good and bad cases [i.e. veridical perceptual experience and hallucination, respectively] have no reasonably specific, fundamental experiential commonalities. A reasonably specific experiential commonality is fundamental just in case it characterizes what the experiences fundamentally consist in, i.e. each experience satisfies all other psychological characterizations ultimately in virtue of having the common property. ${ }^{86}$

\footnotetext{
${ }^{84}$ Husserl, $L I$ 2:I I 2.

${ }^{85}$ Husserl, Hua 3:I39/Ideas I, I67.

${ }^{86}$ Logue, "Good News for the Disjunctivist," I I 2.
} 
The requirement of being reasonably specific nearly goes without saying. The fact that the two kinds of experience, veridical perception and hallucination, are mental states or are conscious fails in this regard, as neither characterization is informative about these kinds of experience as opposed to others. Logue's suggestion, then, is that a disjunctivist can admit commonalities between two kinds of experience as long as they do not include any peculiar or characteristic ("reasonably specific") feature that is fundamental to the two kinds of experience in the sense that all their other features belong to them at bottom because the possess the one in question. Let us call commonalities that are reasonably specific and fundamental in this sense 'conjunctive commonalities,' since their existence entails conjunctivism, and let us call commonalities that do not satisfy that description 'disjunctive.'

We need to ask, then, whether the commonalities Husserl ascribes to veridical perceptual experience and hallucination commit him to a conjunctive or disjunctive view, that is, whether they are conjunctive or disjunctive commonalities. We can do that by figuring out what explains the indistinguishability of certain hallucinations and veridical perceptual experiences. One disjunctive (i.e. nonfundamental) feature they share is their phenomenal character, what it is like to have them. That certainly seems to follow from their indistinguishability, given that we have no reason to think our ability to distinguish them is in any way defective. If what explains this commonality between the two winds up being the same thing, then we have a good candidate for a conjunctive commonality. Disjunctivism, by contrast, can only be maintained if the phenomenal character of veridical perceptual experience and hallucination receive separate explanations appealing to distinct (i.e. unshared) fundamental features. ${ }^{87}$

For Husserl, the sameness of appearance in veridical perceptual experience and hallucination is grounded in an underlying sameness of other more basic features. That is, Husserl seems to attribute conjunctive commonalities to them. I believe that is true of the commonalities I mentioned earlier (i.e. the mode, sense data, and intentional content ['noematic content']) that can feature identically in veridical perceptual experience and hallucination. On some occasions Husserl bundles together the sense data and intentional content, jointly referring to them as "perceptual appearance." With that in mind, here are a few pertinent quotations: ${ }^{88}$

\footnotetext{
${ }^{87}$ Logue, "Good News for the Disjunctivist," I I 5.

${ }^{88}$ In the quoted passages and others cited here, Husserl speaks of both hallucination and illusion. His usage of these terms suggests that he sees no theoretically salient distinction between the two. In Hua 38: 1 25-26, he includes them both under the heading Falschnehmung, the idea being that they are both erroneous experiences, distinctive, says Husserl, due to their ability to bring to intuitive sensory consciousness things that do not exist (Hua 38:I26, I28, I29, I36). Indeed, while Husserl does recognize some difference between illusion and hallucination, he sometimes uses 'illusion' and 'illusionary' as blanket terms for erroneous perceptual experiences (including hallucination), that is, as equivalent to his use of Falschnehmung in Hua 38. Husserl's comments in Hua 23:239, 279, 407/ Phantasy, 293, 337, and 480 are illustrative. In one passage he clarifies his meaning when using the term 'illusionary' as intended to refer to perceptual consciousness of a 'figment,' presumably meaning something nonexistent (Hua 23:242-43/Phantasy, 298). Additionally, in a considerable number of passages Husserl speaks of 'hallucination or illusion' in an indiscriminating way to make generalizing claims about both together (Hua 23:4, 234, 335/Phantasy, 6, 284, 407; Hua 38:10, 82, I23, I2 5; and Hua 3:7I / Ideas I, 83). This suggests that, to his mind, there is no important difference between them as kinds of conscious
} 
The difference between the perception and the illusion of the same appearance content (apprehension content) consists in the fact that in the first case impressional belief and in the second case the modification of belief is interwoven with the same impressional appearance. ${ }^{89}$

But how [do perception and phantasy, i.e. imagination, differ], if I take a perception and an illusion of the same apprehensional content? In the latter case, [there is] a quality degraded by conflict with competing perceptions or empirical experiences to a mere belief tendency, a belief tendency that is no longer belief. What is modified here? Surely only the quality [i.e. mode]. The situation, however, is entirely different from what it is in the case of the phantasy [i.e. imagining] of the same content. ... A bare phantasy may have the "same content" as the former hallucination. What determines the difference? Well, in the one case, there is perceptual appearance; in the other, phantasy appearance..$^{90}$

The illusionary act and the simple perceptual act are about the same essence. In what sense? Well, in the sense that the same thing presents itself from the same side, except that in one case it is uncontested and in the other it is "annulled." ${ }^{\prime 1}$

What Husserl is doing in these passages is providing criteria for sorting out several different types of experience. He is attempting to explain the underlying factors that set apart these in some respects quite similar kinds of experience, namely, perceptual experience, the experience of illusion and hallucination, and imagination.

Note that Husserl is not talking about illusion and hallucination per se here, but only certain instances where experiences give themselves away as being illusory or hallucinatory. In them, "something stands before me as a semblance." ${ }^{\text {" He does not }}$ hold that all illusions and hallucinations are experienced as such, ${ }^{93}$ and he clearly distinguishes illusion and hallucination simpliciter from the experience of them as such. ${ }^{94}$ In the text just quoted from, he grants the possibility of "hallucinations [that] force themselves into the perceptual field and hold their own there as genuine perceptual appearances. ${ }^{.95}$

The main thing to take away from these passages is that experienced hallucination and (veridical) perceptual experience fall into one category and imagination falls into another category. It is safe to assume that hallucination that is not experienced as such also falls into the same category as (veridical) perceptual experience. It cannot even be distinguished from the latter in terms of its mode (i.e. the belief-like quality discussed in section 3.5 above). What justifies lumping perceptual experience and hallucination together is that they can have "the

experience. For these reasons, although some of the passages I quote or cite refer to 'illusion' and not 'hallucination,' I nevertheless take those passages to be informative about the nature of hallucination. (I am grateful to the anonymous reviewer who asked for clarification on this matter.)

${ }^{89}$ Husserl, Hua 23:219/ Phantasy, 268.

${ }^{90}$ Husserl, Hua 23:214/ Phantasy, 263.

${ }^{91}$ Husserl, Hua 23:235/Phantasy, 285.

${ }^{92}$ Husserl, Hua 23:222/ Phantasy, 27I.

${ }^{93}$ Husserl, Hua 23:408/ Phantasy, 480-8I.

${ }^{94}$ Husserl, Hua 23:486-87/Phantasy, $58 \mathrm{I}$.

${ }^{95}$ Husserl, Hua 23:63/Phantasy, 58; see also Hua 23:I I9/Phantasy, I3 I. 
same appearance content" or, even better, "the same impressional appearance." 96 Whether an experience has this impressional element turns on whether its content is integrated with sense data in the right way. ${ }^{97}$ In the case of hallucination and illusion, they are, but in imagination, they are not. Indeed, Husserl says they cannot be. ${ }^{98}$ Hence, imagination falls into another category.

Consider one final point in favor of a conjunctive reading. Not only do veridical perceptual experiences and hallucinations have all the same kinds of intrinsic features (e.g. Leibhaftigkeit, mode, sense data, content), they can have one and the same intentional object (or "noematic X" in the language of Ideas I). By itself, that is not a decisive reason to read Husserl as a conjunctivist. However, it is important in two respects. First, it rounds out the similarities between perceptual experience and hallucination, leaving little room for doubt that they share all their intrinsic essential features. Second, it rules out the version of disjunctivism that Smith and Hopp attribute to Husserl, which, we have seen, is the main rival to the conjunctive reading. Smith's reading, we saw, was that for Husserl veridical perceptual experience and hallucination cannot ever be of one and the same (i.e. token-identical) object.

Husserl contradicts Smith's claim when he writes:

Description of the perceived as such, "as" it is perceived: clearly, distinctly, un-clearly, un-distinctly. And similarly for illusion. The perceived as such is in several, perhaps different perceptions, but it (the "appearance" that is different in both cases) "is related to the same object." 99

Husserl frequently observes that one and the same object can be presented in many ways. That is the point he is making about perceptual experience in this quotation. The remark is a terse recapitulation of an analysis from earlier in the same text, ${ }^{100} \mathrm{a}$ variation of which he presents in a later text as well. ${ }^{101}$ You can perceive a particular object "clearly" at one moment, "unclearly" at another. Further, you can have an "illusory" experience of it. Perhaps you hallucinate it, and the hallucination is experienced as such. What Husserl is saying is that these disparate experiences can all serve to bring us in perceptual contact with the very same object.

In another place, Husserl is even more straightforward about the point. There, he entertains the possibility of hallucinating the presence of someone who has died or who we know to be somewhere far away to illustrate how violations of expectation might function in unmasking the hallucinations as such. ${ }^{102}$ In that case he has no qualms about whether you could veridically perceive and hallucinate one and the same object. Nevertheless, if Smith were right that veridical perceptual experience and hallucination cannot be of token-identical objects, it would still be the case that hallucination is of particulars and identifies them as such, thus sharing the,

\footnotetext{
${ }^{96}$ Husserl, Hua 23:268/Phantasy, 2 I9.

${ }^{97}$ Hua 23:IO-I 2/Phantasy, IO-2; see also Hua 23:80-8I, 222, 227, 237, 244/Phantasy, 87-88, 27I, 226, 29I, 300 .

${ }^{98}$ Husserl, Hua 23:222/Phantasy, 27I.

${ }^{99}$ Husserl, Hua 38:27I, my translation.

${ }^{100}$ Husserl, Hua $38: 233-34$.

${ }^{101}$ Husserl, Hua 38:403.

${ }^{102}$ Husserl, Hua 23:I33/Phantasy, I 47n 43 .
} 
for Husserl, all-important feature of having a "noematic X." Whether or not you are hallucinating, Husserl emphasizes, you may have an experience of "this house here before me and 'outside of' me." 103

In the passages I have been drawing from, Husserl not only likens hallucination to veridical perceptual experience, he by all appearances uses hallucination repeatedly to shed light on the fundamental nature of perceptual experience as a unified and thus non-disjunctive category. From this, I think a general presumption follows that, on Husserl's account, for any significant difference between veridical perceptual experience and imagination, we should expect hallucination to resemble veridical perceptual experience in the relevant respect rather than imagination.

Now, the disjunctivist of a Husserlian stripe might be tempted to liken hallucination to imagination thanks to their fictive character and to import claims about the content of imagination qua fictive that of hallucination. ${ }^{104}$ For instance, Husserl holds that, thanks to their fictive character, imagined objects are only "quasi-individuals," in that they can only be meaningfully described in relation to the imaginary world in which they are embedded and not the real world or any other imagined world. ${ }^{105}$ It might be alleged that hallucinated objects, too, are only quasi-individuals. Then, the disjunctivist might infer, there is some basic difference between veridical perceptual experience and hallucination. The presumption just described, however, cautions against this analogy and, in turn, undermines the disjunctivist-favoring inference.

The presumption, though, certainly is not dispositive. It should put us on guard, however. A closer look at the analogy with imagination reveals its inadequacy. Hansel and Gretel, borrowing Husserl's example, are quasi-individuals in that, as fictional characters, they are individuated relative to some imagined space-time other than our own. So, any claims about them quantify only over that world, and any kind of trans-world identity is ruled out in principle. If this idea were carried over to the analysis of hallucination, it would have to be the case that hallucinated objects are not individuated relative to our world, but rather to a different, nonactual world. They would not be experienced as populating the space of the perceiver or to be temporally coexistent with the perceiver. Things evidently are not that way, and Husserl does not suggest otherwise. As we observed in section 3.5 in discussing modalization, he conceives of hallucination as integrating with veridical perceptual experience in a way that seems utterly at odds with the disjunctivist appeal to imagination.

In light of these considerations, then, what should we say about the phenomenal character of perceptual experience and hallucination? Does it seem likely that Husserl would offer fundamentally distinct and non-overlapping explanations for what it is like to have perceptual experience and hallucination?

I do not think so. In comparing perceptual experience, the experience of illusion and hallucination, and imagination, Husserl makes no reference to

${ }^{103}$ Husserl, Hua 38:I33; Hua 9:22-23/Phenomenological Psychology, 3 I-32; and Husserl, Hua 7:107/First Philosophy, I I0.

${ }^{104}$ I owe this line of response, or something close to it, to an anonymous reviewer.

${ }^{105}$ Husserl, Experience and Judgment, §40. 
systems of possible experience à la Smith's reading. Nor would it be plausible to posit such systems as explanatorily more fundamental than the things he does mention. He appeals instead to their intrinsic properties and above all, their content and whether that content suitably integrates sense data. And it is reasonable to think these are the ultimate ingredients of which systems of possible perceptual experience are constituted and explained and not vice versa. Husserl could argue that veridical perceptual experience and hallucination share these features and that they are fundamental in the case of hallucination but not in the case of veridical perceptual experience, which would put him in the disjunctivist camp. ${ }^{106}$ But he does not do that. In perceptual experience, we seem to hit rock bottom on Husserl's account when we account for it in terms of its intentional content and sensory component. Because these are present in hallucination, too, it follows that the two have conjunctive commonalities and that Husserl's views commit him to conjunctivism.

\section{B I B L I O G R A P H Y A N D A B B R E V I A T I O N S}

Ali, Rami. "Does Hallucinating Involve Perceiving?" Philosophical Studies I75 (2018): 60I-27. DOI: IO.I007/si I098-0I7-0884-7.

Bell, David. "Reference, Experience, and Intentionality." In Mind, Meaning and Mathematics. Edited by Leila Haaparanta, I85-209. Dordrecht: Kluwer, I994.

Bickle, John and Ralph Ellis. "Phenomenology and Cortical Microstimulation." In Phenomenology and Philosophy of Mind, edited by David W. Smith and Amy Thomasson, I40-63. Oxford: Oxford University Press, 2005.

Brewer, Bill. "Perception and Content." European Journal of Philosophy I 4 (20I I): I65-8 I. . Perception and its Objects. Oxford: Oxford University Press, $20 \mathrm{I}$ I.

Brogaard, Berit, ed. Does Perception Have Content? Oxford: Oxford University Press, 2014.

Burge, Tyler. "Disjunctivism and Perceptual Psychology." Philosophical Topics 33 (2005): I-78.

Campbell, John. Reference and Consciousness. Oxford: Oxford University Press, 2002.

Drummond, John. "The Doctrine of the Noema and the Theory of Reason." In Staiti, Commentary on Husserl's Ideas I, 257-7I. ["The Doctrine of the Noema"]

—. "Intentionality without Representationalism." In Zahavi, The Oxford Handbook of Contemporary Phenomenology, I I 5-33.

Farkas, Katalin. "Indiscriminability and the Sameness of Appearance." Proceedings of the Aristotelian Society 106 (2006): 39-59.

Fish, William. Perception, Hallucination, and Illusion. Oxford: Oxford University Press, 2009

Føllesdal, Dagfinn. "Husserl's Theory of Perception." In Husserl, Intentionality, and Cognitive Science, edited by Hubert Dreyfus, 93-96. Cambridge: MIT Press, I983.

Genone, James. "Appearance and Illusion.” Mind I 23 (2014): 339-76.

Gerassi, John. Talking with Sartre: Conversations and Debates. New Haven: Yale University Press, 2009.

Hopp, Walter. Perception and Knowledge: A Phenomenological Account. Cambridge: Cambridge University Press, 20II. [Perception and Knowledge]

Heffernan, George. "The Paradox of Objectless Presentations in Early Phenomenology." In Studia Phaenomenologica, vol. XV, edited by Rodney Parker and Dermot Moran, 67-9I. Bucharest: Zeta Books, 20I 5. ["The Paradox of Objectless Representations"]

Husserl, Edmund. Husserliana: Edmund Husserl-Gesammelte Werke, 47 vols. Edited by Ulrich Melle. Dordrecht: Springer, 1973-2020. [Hua]

—_. Analysen zur passiven Synthesis. Aus Vorlesungs- und Forschungsmanuskripten (I 9 I 8-I926). Edited by Margot Fleischer, in Hua I I. [Hua I I]

- Analyses Concerning Passive and Active Synthesis: Lectures on Transcendental Logic. Edited and translated by Anthony Steinbock. Kluwer: Dordrecht, 200I. [Passive Synthesis]

- Ding und Raum. Vorlesungen I907. Edited by Ulrich Claesges, in Hua I6. [Hua I6]

—. Erste Philosophie (1923/24). Erster Teil: Kritische Ideengeschichte. Edited by Rudolf Boehm, in Hua 7. [Hua 7]

${ }^{106}$ Logue, "Good News for the Disjunctivist," I 3 I-36. 
—. Experience and Judgment. Edited by Ludwig Landgrebe and translated by James Churchill and Karl Ameriks. Evanston: Northwestern University Press, I973.

. First Philosophy: Lectures I923/24 and Related Texts from the Manuscripts (I920-I925). Translated by Sebastian Luft and Thane Naberhaus. Dordrecht: Springer, 20I9. [First Philosophy]

- Ideen zu einer reinen Phänomenologie und phänomenologischen Philosophie. Erstes Buch: Allgemeine Einführung in die reine Phänomenologie. Edited by Karl Schuhmann, in Hua 3. [Hua 3]

—. Logical Investigations, vol. 2. Translated by John N. Findlay and edited by Dermot Moran. London: Routledge, 200I. [LI 2]

. Logische Untersuchungen. Zweiter Band: Untersuchungen zur Phänomenologie und Theorie der Erkenntnis. Edited by Ursula Panzer, in Hua I9. [Hua I9]

. Phänomenologische Psychologie. Vorlesungen Sommersemester 1925. Edited by Walter Biemel, in Hua 9. [Hua 9]

—. Phenomenological Psychology. Lectures, Summer Semester I925. Translated by John Scanlon. The Hague: Martinus Nijhoff, I977. [Phenomenological Psychology]

. Phantasie, Bildbewusstsein, Erinnerung. Zur Phänomenologie der anschaulichen Vergegenwärtigungen.

Texte aus dem Nachlass (I898-I925). Edited by Eduard Marbach, in Hua 23. [Hua 23]

. Phantasy, Image Consciousness, and Memory (I 898-I925). Translated by John Brough. Dordrecht: Springer, 2005. [Phantasy]

- Thing and Space: Lectures of I907. Translated by Richard Rojcewicz. Dordrecht: Kluwer, I997. [Thing and Space]

- Transzendentaler Idealismus: Texte aus dem Nachlass (I908-I92I). Edited by Robin Rollinger and Rochus Sowa, in Hua 36. [Hua 36]

. Wahrnehmung und Aufmerksamkeit: Texte aus dem Nachlass (I893-I9I2). Husserliana vol. 38. Edited by Thomas Vongehr and Regula Giuliani, in Hua 38 . [Hua 38]

Johnston, Mark. "The function of sensory awareness." In Perceptual Experience, edited by Tamar Szabo Gendler and John Hawthorne, 260-90. Oxford: Oxford University Press, 2006.

Logue, Heather. "Experiential content and naïve realism: A reconciliation." In Brogaard, Does Perception Have Content?, 220-4 I. ["Experiential content and naïve realism"]

- "Good News for the Disjunctivist about (One of) the Bad Cases." Philosophy and Phenomenological Research 86 (2013), I05-33. ["Good News for the Disjunctivist"]

Martin, Michael G. F. "The Transparency of Experience." Mind and Language I7 (2002): 376-425.

Marchesi, Andrea. "Husserl's Early Theory of Intentionality as a Relational Theory." Grazer philosophische Studien 3 (20I8): 343-67. DOI: IO.II63/I8756735-000042. ["Husserl's Early Theory of Intentionality"]

McDowell, John. "Criteria, Defeasibility \& Knowledge." Proceedings of the British Academy (I982): 45 5-79.

Meixner, Uwe. "Husserl's Classical Conception of Intentionality" In Husserl and Analytic Philosophy, edited by Guillermo Haddock, 55-86. Berlin: De Gruyter, 2016.

Miller, Izchak. "Perceptual Reference." Synthese 6I (I984): 35-59.

Mohanty, Jitendra N. "Noema and Essence." In The Phenomenology of the Noema, edited by John Drummond and Lester Embree, 49-55. Dordrecht: Kluwer, I992.

Mulligan, Kevin. "Perception." In The Cambridge Companion to Husserl, edited by Barry Smith and David W. Smith, I68-238. Cambridge: Cambridge University Press, I995.

Mulligan, Kevin, and Barry Smith. "A relational theory of the act." Topoi 5 (I986): I I 5-30.

Overgaard, Søren. "Motivating Disjunctivism." Husserl Studies 29 (20I 3): 5 I-63.

. "Perceptual Error, Conjunctivism, and Husserl." Husserl Studies 34 (20I8): 25-45. DOI: IO.I007/sI0743-0I7-92 I 5-2.

Philipse, Herman. "The Concept of Intentionality: Husserl's Development from the Brentano Period to the Logical Investigations." Philosophy Research Archives I3 (I987): 293-328. ["The Concept of Intentionality"]

Poellner, Peter. "Consciousness in the World: Husserlian Phenomenology and Externalism." In The Oxford Handbook of Continental Philosophy, edited by Brian Leiter and Michael Rosen, 409-62. Oxford: Oxford University Press, 2007. ["Consciousness in the World"]

Robinson, Howard. "The Failure of Disjunctivism to Deal with 'Philosophers' Hallucinations." In Hallucination, edited by Fiona Macpherson and Dimitris Platchias, 3 I3-30. Cambridge: MIT Press, 2013 .

Perception. London: Routledge, I994.

Romano, Claude. "Must Phenomenology Remain Cartesian?" Continental Philosophy Review 45 (20 I 2 ): 425-45.

Schellenberg, Susanna. "The Relational and Representational Character of Perceptual Experience." In Brogaard, Does Perception Have Content?, I99-2 I9. 
Smith, A. D. "Husserl and Externalism." Synthese I 60 (2008): 3 I 3-33.

Smith, Barry. "Acta cum Fundamentalis in Re." Dialectica 38 (I984): I 57-78.

Smith, David W. "Perception, Context, and Direct Realism." In Zahavi, The Oxford Handbook of Contemporary Phenomenology, I34-57.

Smith, David W., and Ronald McIntyre. Husserl and Intentionality. Dordrecht: Kluwer, I 982.

Snowdon, Paul. "Perception, Vision and Causation." Proceedings of the Aristotelian Society 8I (I980): I $75-92$.

Sosa, Enest. A Virtue Epistemology. Oxford: Oxford University Press, 2007.

Soteriou, Matthew. Disjunctivism. New York: Routledge, 2016.

Staiti, Andrea, ed. Commentary on Husserl's Ideas I. Berlin: DeGruyter, 2015.

Staiti, Andrea. "On Husserl's Alleged Cartesianism: A Reply to Claude Romano." Husserl Studies 3 I (201 5): I 23-4I. ["On Husserl's Alleged Cartesianism"]

Travis, Charles. "The Silence of the Senses." Mind I I3 (2004): 57-94.

Zahavi, Dan. Husserl's Legacy. Oxford: Oxford University Press, 2017.

, ed. The Oxford Handbook of Contemporary Phenomenology. Oxford: Oxford University Press, $20 \mathrm{I} 2$. . "Phenomenology of Reflection." In Staiti, Commentary on Husserl's Ideas I, I77-79. 
